BMJ Open

Sport \&

Exercise

Medicine

\title{
Symptoms and risk factors of depression during and after the football career of elite female players
}

\author{
Birgit Prinz, ${ }^{1}$ Jiř́ Dvořák, ${ }^{2,3,4}$ Astrid Junge ${ }^{1,2,3}$
}

To cite: Prinz B, Dvořák J, Junge $A$. Symptoms and risk factors of depression during and after the football career of elite female players. BMJ Open Sport Exerc Med 2016;2:e000124. doi:10.1136/bmjsem-2016000124

- Prepublication history for this paper is available online To view these files please visit the journal online (http://dx.doi.org/10.1136/ bmjsem-2016-000124).

Accepted 27 April 2016
CrossMark

${ }^{1}$ Medical School Hamburg (MSH), Hamburg, Germany ${ }^{2}$ FIFA Medical Assessment and Research Centre (F-MARC), Zurich,

Switzerland

${ }^{3}$ Schulthess Clinic, Zurich, Switzerland

${ }^{4}$ Fédération Internationale de Football Association (FIFA), Zurich, Switzerland

Correspondence to

Dr Astrid Junge;

Astrid.Junge@medicalschoolhamburg.de

\section{ABSTRACT}

Background: The mental health of elite athletes has received increasing attention in recent years, but no study has evaluated the career-time prevalence of depression, and very few have analysed risk factors of mental health problems during or after the career.

Methods: 157 (response rate $64.1 \%$ ) female players who played in the German First League answered an anonymous online survey on details of their football career, stressful and helpful conditions, depression and need of psychotherapeutic support during and after the football career.

Results: The career-time prevalence of depression symptoms was $32.3 \%$. Significant differences in the average depression score were observed for playing positions $(F=2.75 ; p<0.05)$ and levels of play $(F=3.53$; $\mathrm{p}<0.01)$. About half of the players $(49.7 \%)$ stated 'conflicts with coach/management' as an important reason for their low in moods, followed by 'low in performance/injury' (48.4\%) and 'too little support/ acknowledgement by the coach' (40.0\%).

'Psychological strain/stress' (46.5\%) was (after injury) the second most important reason for lows in performance. During their career, almost $40 \%$ of players wanted or needed psychological support, but only $10 \%$ received it. After their career, the percentage of players wanting or needing psychological support decreased to $24 \%$, of whom $90 \%$ received it.

Conclusions: The high prevalence of depression symptoms in combination with low use of psychotherapy during the career shows the need for de-stigmatisation of mental health issues in elite football. Furthermore, it seems very important to educate coaches, physicians, physiotherapists and club managers to recognise and prevent mental health problems of their players.

\section{INTRODUCTION}

In recent years, mental health of athletes has received increasing attention in sports medicine, and several editorials, ${ }^{1-4}$ clinical overviews $^{5-8}$ and empirical studies ${ }^{9-24}$ have been published on this topic. It is now accepted that elite athletes are under specific internal and external emotional pressures, and that these stressors may lead to an increased prevalence of mental health problems. ${ }^{3}$

\section{What are the new findings?}

- German elite female football players had a high prevalence of depression symptoms but a low use of psychotherapeutic support during the career.

- The average depression score differed significantly between playing positions and levels of play.

- 'Conflicts with coach/management' was the most frequently stated reason for lows in mood.

- The percentage of players with symptoms of depression and of players wanting or needing psychotherapeutic support decreased after the end of the football career.

How might it impact on clinical practice in the near future?

- Reduction of stigma attached to mental health problems in athletes to increase help seeking.

- Development of effective and low threshold psychotherapeutic support for elite players.

- Education of coaches about their fundamental role for the mental health of their players.

- Improved planning and preparation of the time after the end of the football career.

However, sound epidemiological studies are still rare, and their results are inconclusive. $^{5} 925$ Most studies investigated depression, and some assessed anxiety, eating disorders, abuse of alcohol or unspecific mental health problems such as distress and burnout in active athletes (for an overview, see ref. 25). A few studies examined the present mental health of athletes after the end of their sports career. ${ }^{22}{ }^{26-29}$ Until now, no study has investigated the career-time prevalence of depression or other mental health concerns in elite athletes. Gulliver et $a l^{18}$ asked active athletes whether or not they 'have ever seen a mental health professional to get help for personal or emotional problems'. This might give an indication of 
the size of the problem (overall $57.1 \%$ ); however, the athletes were still within their career, and the study had a low response rate $(25.1 \%)$.

Prior studies have reported a prevalence of depression in athletes ranging between $3.6 \%{ }^{20}$ and $34 \% .^{23}$ These differences might be due to the study population (gender, type of sport, competition level), assessment methods and response rates. ${ }^{25}$ In the eight studies that used the Centre of Epidemiologic Studies Depression Scale (CES-D) ${ }^{30}$ and a cut-off of 15 for classification of depression, ${ }^{11-15} 182425$ the prevalence rates of symptoms of depression varied between $6.6 \%{ }^{25}$ and $33.5 \%,{ }^{11}$ most probably due to the differences in characteristics of the study groups and in response rates. ${ }^{25}$

Risk factors for mental health problems have rarely been investigated in athletes. In most studies, a higher prevalence of depression was reported in female than in male athletes. ${ }^{11} 12$ 17-19 2425 Differences in the prevalence of depression were found for type of sport, ${ }^{24}$ level of play ${ }^{19} 2325$ and player position. ${ }^{25}$ In general, injured players had higher scores of depression than uninjured players. ${ }^{1025} 31$ Gouttebarge et $a l^{22}$ observed that mental health problems were significantly associated with low social support and recent life events. Nixdorf et $a l^{19}$ found a correlation of depression symptoms with chronic stress, coping strategies and stress recovery states. Hammond et $a l^{23}$ reported that twice as many athletes met criteria for a major depressive episode before a competition compared with after a competition.

Since almost all mental health questionnaires relate to a relatively short period of time (eg, CES-D to the past week), such evaluation of active athletes does not reflect the sports career, and might be biased by specific situational conditions. Another important aspect which needs to be considered when assessing mental health in active athletes is the stigma attached to this topic. ${ }^{2}$ It is possible that stigma leads to an under-reporting or denial of mental health problems in active athletes. ${ }^{6}$ 32-34 A retrospective design allows evaluation of the prevalence of depression for the entire period of a sports career and might reduce potential bias or non-compliance expected in active athletes due to the stigma and denial attached to this topic.

A suitable study population should regard the following criteria: (1) one type of sport because of the differences in depression between sports, ${ }^{24}$ (2) a popular sport because of the relevance of the results and (3) a high level of play because of the associated level of stress. ${ }^{19} 23$

Thus, the aims of the present study were to evaluate depression symptoms during and after the career in former female football players of the German First League. Additional questions on stressful and helpful conditions were included to provide ideas for prevention or reduction of mental health problems. Information about reasons for and consequences of ending the sports career might help to improve the care for players beyond their football career.

\section{METHODS}

An anonymous online survey was developed with questions on personal characters, playing position, number of matches, training sessions and injuries during the career, reasons for lows in mood and lows in performance, helpful conditions, reasons for ending the football career, concreteness of plans for the life after the football career, problems in the first 2 years after the end of the football career, and need and use of psychotherapeutic support during and after the football career. Almost all questions had predefined answer choices and an option to insert free text. In addition, a modified version of the CES-D ${ }^{30}$ and of the Patient Health Questionnaire-2 (PHQ-2) ${ }^{35}$ were included.

The CES- $\mathrm{D}^{30}$ is a self-report scale to measure severity of depression symptoms experienced in the past week. On the basis of the answers to the 20 items on a fourpoint Likert scale (0-3), a depression score between 0 and 60 is calculated. The cut-off score for mild-to-moderate depression is 16 , and for a major depression it is more than $21 .{ }^{30}$ The validated German version of the CES-D ${ }^{36}$ was modified as proposed by Cannon $e t a l^{\beta 7}$ to measure career-time depression, that is, in the introduction sentence 'during the past week, including today' was replaced by 'during the worst times playing in the first league', and the wording of response options was kept but the specified numbers of days were deleted.

The PHQ- $2^{38}$ is the short form of the PHQ- $9^{39}$ to assess depression in the past 2 weeks. On the basis of the four-point Likert scale (0-3), a depression score between 0 and 6 is calculated. The cut-off score for depression is $3 .^{38}$ The validated German version of the PHQ-2 ${ }^{40}$ was modified as follows: (1) in the introduction sentence, 'over the last 2 weeks' was replaced by 'the first two years following the end of your career playing top-level football' and (2) the response options of the CES-D ('rarely or not at all', 'sometimes', 'often', 'most or all of the time') were used instead of the original ('not at all', 'several days', 'more than half of the days', 'nearly every day').

The study population was all female football players who played between 2000 and 2013 at least five matches in the German First League (NL) or for the National Team (NT). Contact details were available for 245 of the 396 players who fulfilled the inclusion criteria. These players were contacted via a personal email by the first author (BP) with an explanation of the project, and a request to fill in the anonymous online survey. Prior to answering the survey, the players gave their informed consent. The study has ethics approval (PV4734) of the Medical Association of Hamburg, Germany.

All data were processed using Excel and PSPP. CES-D and PHQ-2 questionnaires with more than 33\% missing values were excluded from the analysis; for questionnaires with fewer missing values, these were replaced with the individual average response. Statistical methods applied were means with SD, frequencies with 
percentage, correlation, t-test and analysis of variance. Significance was accepted at $\mathrm{p}<0.05$.

\section{RESULTS}

A total of 157 (64.1\%) female players answered the questionnaire. Almost all grew up in Germany $(n=144$; $92.9 \%)$ or in other European countries $(n=8 ; 5.16 \%)$. On average, the players were $33.0(\mathrm{SD}=6.25)$ years old, and had played for $8.65(\mathrm{SD}=5.13)$ years in the German FL and/or for the NT. Playing positions were distributed as follows: 57 (36.3\%) defenders, 57 (36.3\%) midfielders, $26(16.6 \%)$ attackers and $17(10.8 \%)$ goalkeepers. During their time with the FL/NT, players had an average of $4.69(\mathrm{SD}=1.37)$ training units per week. Thirty-one $(19.4 \%)$ players had played more than $10 \mathrm{NT}$ matches, 24 (15.5\%) 1-10 NT matches and/or 11-50 international club matches, 57 (36.8\%) 1-10 international club matches and/or more than 50 FL matches, 35 $(22.6 \%)$ 11-50 FT matches, and $9(5.8 \%)$ 5-10 FT matches. On average, the players incurred 13.8 $(\mathrm{SD}=19.94)$ injuries during their career, and stopped playing in the FL or for the NT 6.48 years ago $(\mathrm{SD}=3.56)$.

The average depression score for 'the worst times during their football career' was 18.7 ( $\mathrm{SD}=9.2$; range $1-47)$. Fifty players $(32.3 \%)$ had symptoms of a major depression, and $39(25.2 \%)$ of a mild or moderate depression at least once during their football career. No statistically significant correlation with the depression score was observed for age, number of injuries, duration of the football career or time since the end of the football career. Significant differences in the average depression score were found for playing position $(\mathrm{F}=2.75 ; \mathrm{p}<0.05)$ and level of play $(\mathrm{F}=3.53 ; \mathrm{p}<0.01)$. For details, see figure $1 \mathrm{~A}, \mathrm{~B}$.

Asked for the three most important reasons for their low moods, players ticked 'conflicts with coach/management' $(\mathrm{n}=77 ; 49.7 \%)$, 'low in performance/injury' $(\mathrm{n}=75 ; 48.39 \%)$ and 'too little support/acknowledgement by the coach' $(\mathrm{n}=62 ; 40 \%)$ most frequently, followed by 'separation/divorce, illness or death of a close person' $(\mathrm{n}=23 ; 14.8 \%)$ and 'difficulties/trouble in their partnership/family' ( $\mathrm{n}=22 ; 14.2 \%)$. Other reasons were rare $(<5 \%)$. The more reasons for lows in moods that the players stated, the higher was their average depression score (1 reason: 14.0 ( $\mathrm{SD}=6.68)$; 2 reasons: 18.0 ( $\mathrm{SD}=9.05)$; 3 reasons: 25.0 ( $\mathrm{SD}=8.07) ; \mathrm{F}=6.73 ; \mathrm{p}<0.001)$.

The most important reasons for lows in performance were 'injury' ( $\mathrm{n}=88 ; 56.8 \%)$, 'psychological strain/stress' $(\mathrm{n}=72 ; 46.5 \%)$ and 'missing of inner drive' $(44 ; 28.4 \%)$.

The majority of players reported that friends $(n=111$; $71.6 \%)$ and family $(\mathrm{n}=106 ; 68.4 \%)$ were most important to cope with low moods, followed by teammates $(n=59$; $38.1 \%)$, relaxation/rest/retreat $(\mathrm{n}=45 ; 29.0 \%)$, distraction $(\mathrm{n}=38 ; 24.5 \%)$, training/physical activity $(\mathrm{n}=34$; $22.9 \%)$ and hobby $(\mathrm{n}=18 ; 11.6 \%)$. Other factors were of minor importance. Sixty $(38.7 \%)$ players stated that they wanted or needed psychotherapeutic support during their career. These players had a significantly higher
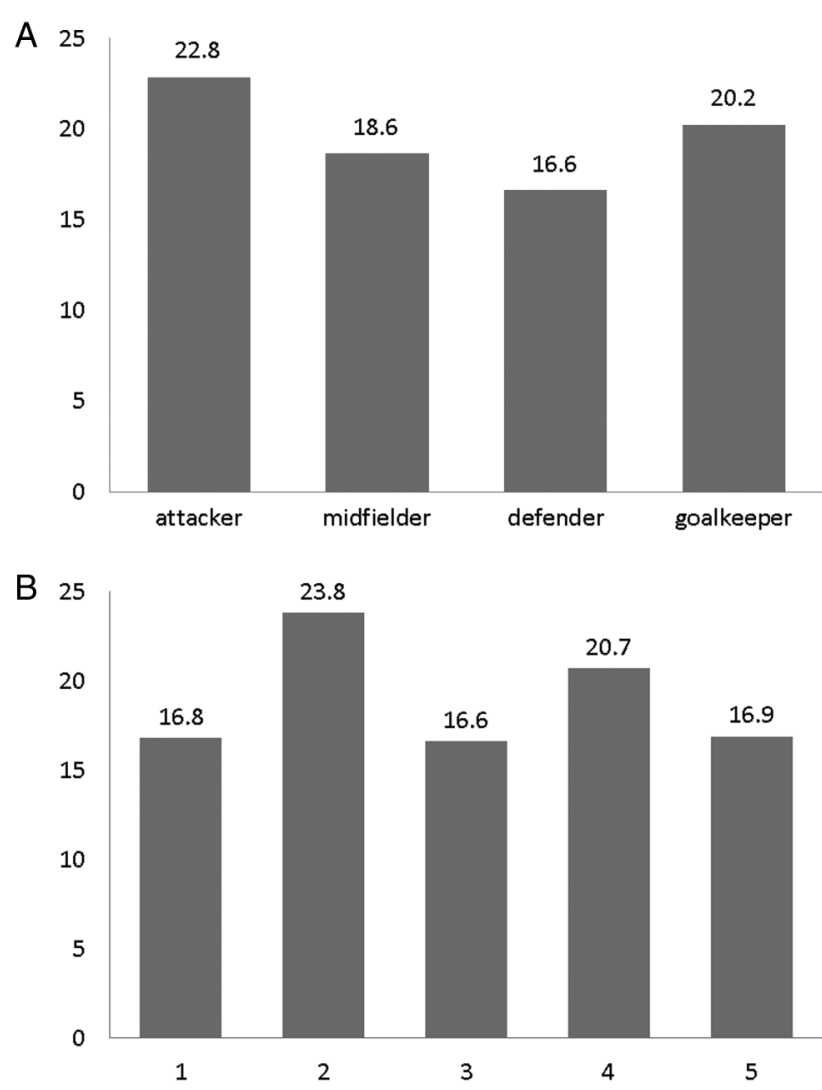

Figure 1 (A) Average depression score (modified Centre of Epidemiologic Studies Depression Scale (CES-D)) for different playing positions. (B) Average depression score (modified CES-D) for level of play (1: $>10$ national team matches; 2: 1-10 national team matches/11-50 international club matches; 3 : $1-10$ international club/ $>50$ national league matches; 4: $11-50$ national league matches; 5 : 5-10 national league matches).

mean value of depression for the worst times of their career (23.6; $\mathrm{SD}=8.65)$ than players who did not want or need psychotherapy during their career $(14.3$; $\mathrm{SD}=7.16$; $\mathrm{t}=6.64 ; \mathrm{p}<0.001)$. However, only $15(9.93 \%)$ players had counselling or treatment by a psychologist or psychotherapist during their career.

When ending their career in the FL/NT, more than half of the players $(n=82 ; 52.9 \%)$ had an exact plan for their life, $45(29.0 \%)$ had some concrete ideas, 18 $(11.6 \%)$ were just vague and $6(3.87 \%)$ had no ideas. The most important reasons for ending their football career are presented in table 1 .

In the first 2 years after their football career, more than a quarter of the players $(n=41 ; 27.3 \%)$ were bothered by injuries or physical symptoms, $31(20.7 \%)$ by feeling low, $26(17.3 \%)$ by too much spare time and a few reported other problems, such as no tasks, family or financial problems. However, $66 \quad(44.0 \%)$ players reported no problems. The average depression score for this time was 0.87 ( $\mathrm{SD}=1.21$; range $0-6) ; 13$ players $(8.5 \%)$ were classified as depressed. Players with more injuries $(\mathrm{r}=0.20 ; \mathrm{p}<0.01)$ and high depression scores $(\mathrm{r}=0.31 ; \mathrm{p}<0.001)$ during their career had higher scores 
Table 1 Most important (up to three) reasons for ending the football career

\begin{tabular}{lrl}
\hline Reason & N & Percentage \\
\hline I wanted more of a private life & 74 & 47.74 \\
I did not want the physical strain & 48 & 31.00 \\
anymore & & \\
Good opportunity to change careers & 42 & 27.10 \\
Serious injury & 36 & 23.23 \\
I did not want the psychological strain & 31 & 20.00 \\
(pressure, stress) anymore & & \\
Fatigued (tired, lacking in energy, burnt & 27 & 17.42 \\
out) & 19 & 12.26 \\
Chronic physical complaints & 20 & 12.90 \\
Changed to a lower division & 16 & 10.32 \\
High demands in job/study & 15 & 9.68 \\
Decline in performance & 13 & 8.39 \\
Club related reasons (insolvency, lower & & \\
or no salary, relegation, Contract was & & \\
not extended) & 7 & 4.52 \\
Change of residence/stay abroad & 13 & 8.39 \\
\hline Other reasons & & \\
\hline
\end{tabular}

of depression for the first 2 years after their career. The average depression score for the first 2 years after the career decreased significantly $(\mathrm{F}=7.56 ; \mathrm{p}<0.001)$ with the concreteness of future plans at the end of their football career: 'no plans' (1.83; $\mathrm{SD}=1.94)$, 'vague plans' (1.94; $\mathrm{SD}=1.59)$, 'some concrete ideas' $(0.84 ; \mathrm{SD}=1.21)$ and 'an exact plan' $(0.57 ; \mathrm{SD}=0.86)$. Thirty $(20.0 \%)$ players had counselling or treatment by a psychologist or psychotherapist after their career, which is about $90 \%$ of all players who wanted or needed this. At the time they filled in the questionnaire, more than half of the players $(\mathrm{n}=85,56.0 \%)$ felt better, $61(39.9 \%)$ the same, and $5(3.27 \%)$ felt worse than in the 2 years immediately after their career.

\section{DISCUSSION}

This is the first study on symptoms and risk factors of depression during and after the football career of elite female players. Almost a third of the players investigated had symptoms of a major depression at least once during their football career. This is higher than the lifetime prevalence of major depression in women of the general population diagnosed using face-to-face interviews; ${ }^{41}{ }^{42}$ however, the prevalence rates differed substantially between studies. The 1-week prevalence of depression symptoms varied in the general German female population $\left(12 \%,{ }^{43} 26 \%\right)^{44}$ in a similar range than in cross-sectional studies on active female athletes (eg, $\left.13 \%,{ }^{25} 25.6 \%,{ }^{12} 28.1 \%,{ }^{24} 30.5 \%\right) .{ }^{18}$

The average depression scores differed significantly between playing positions with forwards and goalkeepers being at the highest risk. The higher risk of depression symptoms of forwards has been reported previously for active female and male football players of the Swiss top leagues. ${ }^{25}$ A potential explanation is that forwards and goalkeepers are often in the focus of the coach and the spectators, since their performance seems to be decisive for the match, that is, forwards have to score the goal, goalkeepers have to prevent it. This could put further pressure and stress on players in these positions and thus increase their risk of depression. The important role of the coach for the emotional status of the players is well reflected in the result of this study that 'conflicts with coach/management' and 'too little support support/acknowledgement by the coach' were the first and third frequent reasons of the players for low moods.

Players classified second highest or second lowest in level of play had higher depression scores than others, possibly because these players can either be promoted or relegated and thus are under great pressure to succeed. Hammond et $a l^{23}$ reported that significantly more athletes who were ranked in the top $25 \%$ of the sample (as contrasted with the remaining 75\%) met diagnostic criteria for major depression. While the results seem to be contradictory, they can be explained when regarding the different structure in football and swimming. Only the best $5 \%$ of the top $25 \%$ of swimmers can be sure to qualify for the national team, while the remaining $20 \%$ are in a similar situation as the second highest level of football players. Junge and Feddermann-Demont ${ }^{25}$ found an increase in the average depression score with a lower of level of play in Swiss female First League and male U-21 football players.

Almost half of the players stated that 'conflicts with coach/management' and $40 \%$ that 'too little support support/acknowledgement by the coach' was an important reason for their lows in mood, while only $5 \%$ of the players mentioned the coach as helpful in coping with lows in mood. Previous studies have mentioned the low social support by the coach, athletic trainer and teammates as a risk factor for symptoms of depression. ${ }^{13} 22$ Coaches should be aware of their important role in the mental health of their players, and should be better educated in management of conflict with and social support of their players.

Interestingly, players reported that 'psychological strain/stress' and 'missing of inner drive' were the second and third most important reasons (after 'injury') for their lows in performance. Thus, mental coaching to improve coping with stress could be another important aspect to be included in the coach education or advanced training, and might help to prevent injuries and/or lows in performance of players.

Almost $40 \%$ of the players stated that they wanted or needed psychotherapeutic support during their career, but only $10 \%$ received counselling or treatment by a psychologist or psychotherapist during this time. Gulliver et $a l^{18}$ reported that $62.7 \%$ of active Australian female athletes saw a psychologist, and $5.9 \%$ a psychiatrist 'to get help for personal or emotional problems'. Future studies should evaluate which reasons prevented German players from seeking help, and low threshold services should be provided. 
In the first 2 years after their career, $8.5 \%$ of the elite female players reported symptoms of depression. Gouttebarge $e t a t^{22}$ found that more former (39\%) than active (26\%) professional male football players had symptoms of depression/anxiety, while Weigand et $a l^{16}$ reported a lower rate of depression in former $(8.0 \%)$ than in current $(16.8 \%)$ college athletes. Owing to the different design and assessment methods of the studies the results cannot be compared, but it seems that the female players participating in this study had better mental health after than during their career, for example, the percentage of players who wanted or needed psychotherapeutic support dropped almost by substantially after the career (24\%) compared to during the career $(40 \%)$.

Players with more concrete plans for the time after their career had lower depression scores than players with no or vague plans. This stresses the importance of specific planning and preparation of the time after the end of the career in elite sport, and for provision of support to athletes whose careers ended unexpectedly. Further, players with higher depression scores in the worst times of their career were more likely to have mental health problems after their career. Thus, it is of great importance that active players with mental health problems receive adequate treatment. In this study, only a quarter of the players who wanted or needed psychological counselling or treatment received it during their career but $90 \%$ of the players in need after the career. Several reasons might have prevented the players in need from getting psychotherapeutic support during the career, including time constraints, availability of qualified therapists and stigma. ${ }^{34}$ The majority of players reported that friends and/or family were most important to cope with their lows in mood, while only $3(2 \%)$ players mentioned professional help by a psychologist, physician or psychotherapist, and $2(1.3 \%)$ players considered medication among the three most important sources of support. Thus, it is important to reduce stigma, as well as to offer effective psychotherapeutic care and/or pharmacological treatment for elite athletes.

\section{Strengths and limitations}

This is the first study investigating career-time prevalence of depression symptoms as well as stressful and helpful conditions to develop interventions to prevent or reduce mental health problems in elite athletes. The retrospective design was chosen for the following reasons: first, the aim was to evaluate the prevalence of depression symptoms during the entire period of an elite sports career, and a retrospective assessment is a common method to assess lifetime prevalence rates, due to the practical problems of long-term observational studies. Second, mental illness is still a stigmatised topic, especially in active top-level athletes, ${ }^{2}{ }^{33}$ and thus an anonymous retrospective survey of mental health might reduce the bias due to stigma and denial. A recall bias is possible due to the retrospective design but unlikely since no correlation was observed between the depression score and the time since the start or the end of the career.

The study population had the following strengths: (1) one type of sport only, because of the differences in depression symptoms between sports, ${ }^{24}$ (2) football because of the great popularity of this sport, and (3) German players because of their high level of play (winner of the Fédération Internationale de Football Association (FIFA) Women's World Cup 2003 and 2007). The response rate $(64.1 \%)$ was within the range of studies in active athletes $\left(25.1 \%{ }^{18}\right.$ to $\left.97.8 \%\right) .{ }^{25}$ A potential selection bias cannot be excluded but might be smaller in this study than in others because the project focused on mental health and on the long-term consequences on physical health. ${ }^{45}$

\section{CONCLUSION}

This study showed a high prevalence of depression symptoms and low use of psychological counselling or treatment in German female football players during their career. Thus, it is important to encourage players to seek psychotherapeutic support when needed, and to provide access to adequate counselling and therapy. 'Conflicts with coach/management' and 'too little support by the coach' were important reasons for players' lows in mood. Therefore, it is essential to educate coaches and managers of the club on how to solve conflicts with players, and how to support their players to reduce mental health problems.

Some player characteristics (such as playing position, level of play) were associated with more depression symptoms. Prospective studies in active players are required to analyse the cause-effect relation, to evaluate the predictive value of the proposed risk factors and, last but not least, to develop, implement and prove the effect of preventive interventions.

Acknowledgements The authors thank the clubs for supporting the study. They highly appreciate the cooperation of all the participating players who volunteered their time to fill in the questionnaire to provide the data for this project. The authors gratefully acknowledge the Fédération Internationale de Football Association (FIFA) for funding this study.

Contributors BP substantially contributed to the design of the study, developed and finalised the questionnaire, contacted the clubs and players with regard to data collection, analysed the data, interpreted the results, drafted the manuscript, and approved of the final version of the manuscript. JD substantially contributed to the concept of the project and the design of the study, discussed the interpretation of results, and approved of the final version of the manuscript. AJ substantially contributed to the concept of the project and the design of the study, reviewed and finalised the questionnaire, discussed the interpretation of results, wrote and revised the manuscript.

Funding Fédération Internationale de Football Association.

Competing interests None declared.

Patient consent Obtained.

Ethics approval Medical Association of Hamburg, Germany.

Provenance and peer review Not commissioned; externally peer reviewed.

Data sharing statement No additional data are available. 
Open Access This is an Open Access article distributed in accordance with the Creative Commons Attribution Non Commercial (CC BY-NC 4.0) license, which permits others to distribute, remix, adapt, build upon this work noncommercially, and license their derivative works on different terms, provided the original work is properly cited and the use is non-commercial. See: http:// creativecommons.org/licenses/by-nc/4.0/

\section{REFERENCES}

1. Malcolm D, Scott A. Suicide, sport and medicine. Br J Sports Med 2012;46:1092-3

2. Bauman NJ. The stigma of mental health in athletes: are mental toughness and mental health seen as contradictory in elite sport? Br J Sports Med 2016;50:135-6.

3. Rao AL, Hong ES. Understanding depression and suicide in college athletes: emerging concepts and future directions. $\mathrm{Br} J$ Sports Med 2016;50:136-7.

4. Trojian T. Depression is under-recognised in the sport setting: time for primary care sports medicine to be proactive and screen widely for depression symptoms. Br J Sports Med 2016;50:137-9.

5. Reardon CL, Factor RM. Sport psychiatry. Sports Med 2010;40:961-80.

6. Glick ID, Stillman MA, Reardon $\mathrm{CL}$, et al. Managing psychiatric issues in elite athletes [CME]. J Clin Psychiatry 2012;73: 640-4.

7. Markser VZ. Sport psychiatry and psychotherapy. Mental strains and disorders in professional sports. Challenge and answer to societal changes. Eur Arch Psychiatry Clin Neurosci 2011;261:182-5.

8. Bar KJ, Markser VZ. Sport specificity of mental disorders: the issue of sport psychiatry. Eur Arch Psychiatry Clin Neurosci 2013;263 (Suppl 2):S205-10.

9. Frank R, Nixdorf I, Beckmann J. Depression among elite athletes: prevalence and psychological factors. Deut $Z$ Sportmed 2013;64:320-6.

10. Wolanin A, Gross M, Hong E. Depression in athletes: prevalence and risk factors. Curr Sports Med Rep 2015;14:56-60.

11. Armstrong S, Oomen-Early J. Social connectedness, self-esteem, and depression symptomatology among collegiate athletes versus nonathletes. J Am Coll Health 2009;57:521-6.

12. Yang J, Peek-Asa C, Corlette JD, et al. Prevalence of and risk factors associated with symptoms of depression in competitive collegiate student athletes. Clin J Sport Med 2007:17:481-7.

13. Yang J, Cheng G, Zhang $Y$, et al. Influence of symptoms of depression and anxiety on injury hazard among collegiate American football players. Res Sports Med 2014;22:147-60.

14. Proctor SL, Boan-Lenzo C. Prevalence of depressive symptoms in male intercollegiate student-athletes and nonathletes. J Clin Sport Psychol 2010:4:204.

15. Brewer B, Petrie T. A comparison between injured and uninjured football players on selected psychosocial variables. Acad Athlete $J$ 1995;10:11-18.

16. Weigand S, Cohen J, Merenstein D. Susceptibility for depression in current and retired student athletes. Sports Health 2013;5:263-6.

17. Storch EA, Storch JB, Killiany EM, et al. Self-reported psychopathology in athletes: a comparison of intercollegiate student-athletes and non-athletes. J Sport Behav 2005;28:86-97.

18. Gulliver A, Griffiths KM, Mackinnon A, et al. The mental health of Australian elite athletes. J Sci Med Sport 2015;18:255-61.

19. Nixdorf I, Frank R, Hautzinger M, et al. Prevalence of depressive symptoms and correlating variables among German elite athletes. $J$ Clin Sport Psychol 2013;7:313-26.

20. Schaal K, Tafflet M, Nassif H, et al. Psychological balance in high level athletes: gender-based differences and sport-specific patterns. PLOS ONE 2011;6:e19007.

21. Spengler A, Schneider G, Schröder E. Depressivität-Screening und Vorkommen in der sportmedizinischen Praxis. Dtsch $Z$ Sportmed 2013:64:65-8.
22. Gouttebarge V, Frings-Dresen MH, Sluiter JK. Mental and psychosocial health among current and former professional footballers. Occup Med (Lond) 2015;65:190-6.

23. Hammond $\mathrm{T}$, Gialloreto $\mathrm{C}$, Kubas $\mathrm{H}$, et al. The prevalence of failure-based depression among elite athletes. Clin J Sport Med 2013;23:273-7.

24. Wolanin A, Hong E, Marks D, et al. Prevalence of clinically elevated depressive symptoms in college athletes and differences by gender and sport. Br J Sports Med 2016;50:167-71.

25. Junge A, Feddermann-Demont N. Prevalence of depression and anxiety in top-level male and female football players. BMJ Open Sport Exerc Med 2016;2:e000087.

26. Schwenk TL, Gorenflo DW, Dopp RR, et al. Depression and pain in retired professional football players. Med Sci Sports Exerc 2007:39:599-605

27. Gouttebarge V, Aoki H, Kerkhoffs GM. Prevalence and determinants of symptoms related to mental disorders in retired male professional footballers. J Sports Med Phys Fitness 2015.

28. Nicholas SJ, Nicholas JA, Nicholas C, et al. The health status of retired American football players: super Bowl III revisited. Am J Sports Med 2007;35:1674-9.

29. Simon JE, Docherty CL. Current health-related quality of life is lower in former Division I collegiate athletes than in non-collegiate athletes. Am J Sports Med 2014;42:423-9.

30. Radloff LS. The CES-D scale a self-report depression scale for research in the general population. Appl Psych Meas 1977:1:385-401.

31. Putukian M. The psychological response to injury in student athletes: a narrative review with a focus on mental health. $\mathrm{Br} \mathrm{J}$ Sports Med 2016:50:145-8.

32. Watson JC. College student-athletes' attitudes toward help-seeking behavior and expectations of counseling services. J Coll Stud Develop 2005;46:442-9.

33. Schwenk TL. The stigmatisation and denial of mental illness in athletes. Br J Sports Med 2000;34:4-5.

34. Gulliver A, Griffiths KM, Christensen $\mathrm{H}$. Barriers and facilitators to mental health help-seeking for young elite athletes: a qualitative study. BMC Psychiatry 2012;12:157.

35. Kroenke K, Spitzer RL, Williams JB. The Patient Health Questionnaire-2: validity of a two-item depression screener. Med Care 2003:41:1284-92.

36. Hautzinger M. Die CES-D Skala: Ein Depressionsmessinstrument für Untersuchungen in der Allgemeinbevölkerung. Diagnostica 1988;34:167-73.

37. Cannon DS, Tiffany ST, Coon $\mathrm{H}$, et al. The PHQ-9 as a brief assessment of lifetime major depression. Psychol Assess 2007;19:247.

38. Löwe B, Kroenke K, Gräfe K. Detecting and monitoring depression with a two-item questionnaire (PHQ-2). J Psychosom Res 2005:58:163-71.

39. Kroenke K, Spitzer RL, Williams JB. The PHQ-9: validity of a brief depression severity measure. J Gen Intern Med 2001;16:606-13.

40. Gräfe K, Zipfel S, Herzog W, et al. Screening psychischer Störungen mit dem "Gesundheitsfragebogen für Patienten (PHQ-D)". Diagnostica 2004:50:171-81.

41. Desai HD, Jann MW. Major depression in women: a review of the literature. J Am Pharm Assoc (Wash) 2000;40:525-37.

42. Andrade L, Caraveo-Anduaga JJ, Berglund $\mathrm{P}$, et al. The epidemiology of major depressive episodes: results from the International Consortium of Psychiatric Epidemiology (ICPE) Surveys. Int J Methods Psychiatr Res 2003;12:3-21.

43. Stein J, Luppa M, Mahnke J, et al. Screening for depression by telephone using the German version of the Center for Epidemiological Studies Depression Scale (CES-D). Psychiatr Prax 2014;41:135-41.

44. Hautzinger M, Bailer M, Hofmeister D, et al. Allgemeine Depressions Skala. Manual. 2. überarbeitete und neu normierte Auflage. Göttingen: Hofgrefe Verlag GmbH \& Co KG, 2012.

45. Prien A, Prinz B, Dvorak J, et al. Long-term health problems in former elite female football players. Prevalence of and risk factors. Scand J Med Sci Sports 2015; [in press] 